\title{
Research on Risks Assessment and Warning System of Local Government Debts
}

\author{
Yan Pan \\ School of Economics and Management \\ Fuzhou University \\ Fuzhou, Fujian, China
}

\author{
Xiaojing Liu* \\ School of Economics and Management \\ Fuzhou University \\ Fuzhou, Fujian, China \\ liuxiaojing126@126.com
}

\begin{abstract}
With the development of social economy, risks assessment and warning system of local government debts have imperiled economy security as well as society steadiness. In order to solve the problem, a risks assessment and warning system of local government debts is analyzed to produce some suggests. This paper is an overview and discussion some important assessment methods for local government debts risks. Firstly, a basic theoretical model of risks assessment is proposed based on literature review. Secondly, an assessment and warning system of local government debts is presented. Then, this paper puts forward the Fuzzy Analytic Hierarchy Process (FAHP) method to determine the degree of importance of each index of risks assessment. Finally, the validity and practicability of risks assessment and warning system is verified after the model had been applied to the practice of a local government debt.
\end{abstract}

Keywords—risks assessment; warning system; local government debts; fuzzy analytic hierarchy process

\section{INTRODUCTION}

During the last decade, China has undergone tremendous economic changes, most of which have greater success in development. Compared with other emerging economies whose government debt has declined significantly, China's government debt mostly held domestically and continues to increase [1]. Thus, the local government debts assessment and warning is a sensitive topic in modern society. Risks assessment and warning system can raise funds for the local government effectively, and reach the aim of regulating the local economy developed at surprising speed. Many local governments began to worry about their public debts. So the research on the assessment and warning of local government debts is very realistic [2]. Therefore, some policy advice about warning system and local debts management to prevent the local government debts risk were presented in this paper.

In addition, many studies have argued for the risks assessment and warning system to alleviate the problem stemming from local government debts policies. And the assessment and warning system of local government debt itself has lots of limitations, which bring much more challenges [3]. It is shown that these pioneering reports on risks assessment system of local government debts were implemented in conjunction with the introduction of an assessment and warning standard. However, while risks assessment and warning system does not hold, we can obtain a weaker result of local government debts [4]. A lot of studies on local government debts were from the standpoint of qualitative evaluation and discoursed upon the application of debts and risks assessment. It is noted that there has been strong advocacy to report on risks assessment and warning in numerous professional and local governmental documents [5]. As briefly discussed in the introduction, this paper will argue that the direction in which local government seeks to steer these processes of economic modernization construction.

The organization of the paper is as follows. The section below introduces the mode of assessment and warning system for local government debts. The next section discusses the significance of risks assessment of local government debts and the related reporting proposals. The last section concludes.

\section{RISKS ASSESSMENT AND WARNING SYSTEM OF LOCAL GOVERNMENT DEBTS}

In this section, we discuss how to build the assessment and warning system of local government debts. We can indeed evaluate the risks impact in its isolation by assuming that the structure of assessment and warning system is given. The purpose of this paper is to develop a structured model to understand risks assessment preferences of local government debts. The risks assessment will help decision makers develop a better understanding of local government debts and identify their own strengths and weaknesses.

In this paper, we show that local government debts will hold at the normal level if the local debts risks are acceptable. Analysis of risks assessment suggests that there is a need to consider more closely the concept of warning system. In this paper, we theoretically consider the impact of assessment system of local government debts. To do so, we consider the interaction of four factors, a size risk, structural risk, solvency risk and economic risk of local government debts.

The aim of this paper is to theoretically investigate the risks assessment and warning system of local government debts. Moreover, local government appears to have been the area of economic policy in which it was susceptible to debt risks. Under the framework that integrates these four factors, we investigate the impact of the third factors including 11 influence factors. 
A FAHP model arranges key variables into a systematic decision hierarchy. The results in the assessment and warning system of local government debts are presented in Table I.

TABLE I. RISKS ASSESSMENT SYSTEM OF LOCAL GOVERNMENT DEBTS

\begin{tabular}{|c|c|c|}
\hline \multirow{11}{*}{$\begin{array}{l}\text { Risks of Local } \\
\text { Government Debts }\end{array}$} & \multirow{3}{*}{ Size Risk } & Debt Rate \\
\hline & & Debt Ratio \\
\hline & & Debt Dependency \\
\hline & \multirow{3}{*}{ Structural Risk } & Contingent Liabilities \\
\hline & & Liabilities for Guarantee \\
\hline & & Related Debt Ratio \\
\hline & \multirow{2}{*}{ Solvency Risk } & Debt Service Ratio \\
\hline & & Overdue Debt Ratios \\
\hline & \multirow{3}{*}{ Economic Risk } & Financial Deficit \\
\hline & & Tax Revenue Ratio \\
\hline & & GDP Growth \\
\hline
\end{tabular}

It can be discerned from the table that its first level of attributes contains risks of local government debts. The second level of attributes focuses on corporate performance: size risk, structural risk, solvency risk and economic risk. The decisional level at the bottom of the FAHP model contains 11 assessment standards.

In addition, the following objectives were set in order to study risks assessment and warning system in local government debts. In this paper, the AHP was developed to solve complex decision-making problems including the ranking and choosing of alternatives [6]. A hierarchy at several levels is a structure consisting of several levels representing the composition of the overall objective. A fuzzy set theory-based AHP approach is employed since it is able to capture subjective preference of risks assessment and warning system [7]. The Fuzzy Analytic Hierarchy Process (FAHP) has been forming by using the fuzzy idea and fuzzy method which are introduced to AHP theory and method [8].

Moreover, the research of FAHP is an important theme for discussion in recently years [9]. Through the application of FAHP on the intersection of different fields, there will be more comprehensive evaluation system for management decision problems [10]. The FAHP was combined with fuzzy comprehensive evaluation to establish the assessment model of local government debts. And the relative weight of the all indexes is determined by using FAHP for more scientific assignment of weights based on the expert's opinion.

This paper applies the new FAHP model to answer this research question. Constructing the FAHP model for risk assessment and warning system, this paper gives a specific evaluation process and step in the following.

Step 1: Constructing triangular fuzzy judgment matrix

Firstly, the priority problems of triangular fuzzy number complementary judgment matrix are studied. Therefore, the judgment standard based on triangular fuzzy number is shown in Table II.

TABLE II. THE JUDGMENT STANDARD BASED ON TRIANGULAR FUZZY NUMBER

\begin{tabular}{ccc}
\hline Compare index & $\begin{array}{c}\text { Triangular fuzzy } \\
\text { number }\end{array}$ & $\begin{array}{c}\text { Reciprocal triangular } \\
\text { fuzzy number }\end{array}$ \\
\hline Prime important & $(9,9,9)$ & $(1 / 9,1 / 9,1 / 9)$ \\
Very important & $(6,7,8)$ & $(1 / 8,1 / 7,1 / 6)$ \\
Comparatively important & $(4,5,6)$ & $(1 / 6,1 / 5,1 / 4)$ \\
General important & $(2,3,4)$ & $(1 / 4,1 / 3,1 / 2)$ \\
Equally important & $(1,1,1)$ & $(1,1,1)$ \\
\hline
\end{tabular}

In this paper, the fuzzy triangular judgment number is adopted to investigate the experts' suggestions, which can be used to determine the index weight. Then, the judgment matrix based on triangular fuzzy number was presented, and each factor's combination weight is calculated dynamically based on the policy set. As to the multi-attribute decision making problem, triangular fuzzy number judgment matrix was used to calculate the constraints. The triangular fuzzy number was selected to construct the judgment matrix based on the fuzzy theory in the following:

$$
\mathrm{M}_{\mathrm{ij}}=\left[\begin{array}{cccc}
(1,1,1) & \left(x_{12}, y_{12}, z_{12}\right) & \cdots & \left(x_{1 n}, y_{1 n}, z_{1 n}\right) \\
\left(\frac{1}{x_{12}}, \frac{1}{y_{12}}, \frac{1}{z_{12}}\right) & (1,1,1) & \cdots & \left(x_{2 n}, y_{2 n}, z_{2 n}\right) \\
\vdots & \vdots & \ddots & \vdots \\
\left(\frac{1}{x_{1 n}}, \frac{1}{y_{1 n}}, \frac{1}{z_{1 n}}\right) & \left(\frac{1}{x_{2 n}}, \frac{1}{y_{2 n}}, \frac{1}{z_{2 n}}\right) & \cdots & (1,1,1)
\end{array}\right]
$$

Where, $i=1,2, \ldots, m ; j=1,2, \ldots, n$. And the inverse matrix is given as:

$$
\sum_{j=1}^{n} \tilde{T}_{i j}^{k}=\left(\sum_{j=1}^{n} x_{i j}, \sum_{j=1}^{n} y_{i j}, \sum_{j=1}^{n} z_{i j}\right)
$$

\section{Step 2: Computing triangular fuzzy number}

In order to decrease the uncertainty of judgment effectively, the mean value of triangular fuzzy number can be described. The triangular fuzzy number is:

$$
\tilde{R}_{i}^{k}=\sum_{j=1}^{n} \tilde{T}_{i j}^{k} \otimes\left(\sum_{i=1}^{n_{k}} \sum_{i=1}^{n_{k}} \tilde{T}_{i j}^{k}\right)^{-1}
$$

In this context, $i, j=1,2, \ldots, n_{\mathrm{k}}$.

Step 3: Sorting hierarchical single

After calculating the synthetic level value to order in single level and whole system, the rank of risks assessment index of 
local government debts can be get at the same time. The degree of possibility is defined as:

$$
\begin{aligned}
& U\left(R_{i}^{k} \geq R_{j}^{k}\right)= \\
& \min \left[U\left(R_{i}^{k} \geq R_{1}^{k}\right), \ldots, U\left(R_{i}^{k} \geq R_{j}^{k}\right), \ldots, U\left(R_{i}^{k} \geq R_{n_{k}}^{k}\right)\right]
\end{aligned}
$$

Then the weight vector is given in following:

$$
W_{k}^{\prime}=\left(U_{1}^{\prime}\left(R_{i}^{k} \geq R_{j}^{k}\right), U_{2}^{\prime}\left(R_{i}^{k} \geq R_{j}^{k}\right), \ldots, U_{n}^{\prime}\left(R_{i}^{k} \geq R_{j}^{k}\right)\right)^{T}
$$

Step 4: Normalizing weight vectors

Based on analysis of many normalization algorithm, the normalized weight vectors are:

$$
W_{k}=\left(U_{1}\left(R_{i}^{k} \geq R_{j}^{k}\right), U_{2}\left(R_{i}^{k} \geq R_{j}^{k}\right), \ldots, U_{n}\left(R_{i}^{k} \geq R_{j}^{k}\right)\right)^{T}
$$

where $W$ is a non-fuzzy number. This dissertation will discuss the FAHP based on trapezoidal fuzzy numbers.

Based on fuzzy mathematics, combine fuzzy integral and AHP, a kind of multiple attributions problem of risks assessment is proposed in this paper.

\section{A CASE STUDY}

A case study illustrated how to risks assessment and warning by using an example of best practice implementations. The purpose of this paper is to stimulate further debate around this subject area with particular focus on a case study of risks assessment and warning of local government debts. Data were collected from tables compiled by the scholar and government reports found in various detailed statistics. The data obtained from different divisions provide preliminary evidence of the value of risks assessment under local government control of the economy. After the data were obtained for each of the index system to be evaluated at a deeper level.

According to the development of risks assessment presently of local government debts, the risk evaluation methods based on FAHP is proposed. And the proposed model for risks assessment and warning system of local government debts is shown in Fig. 1.

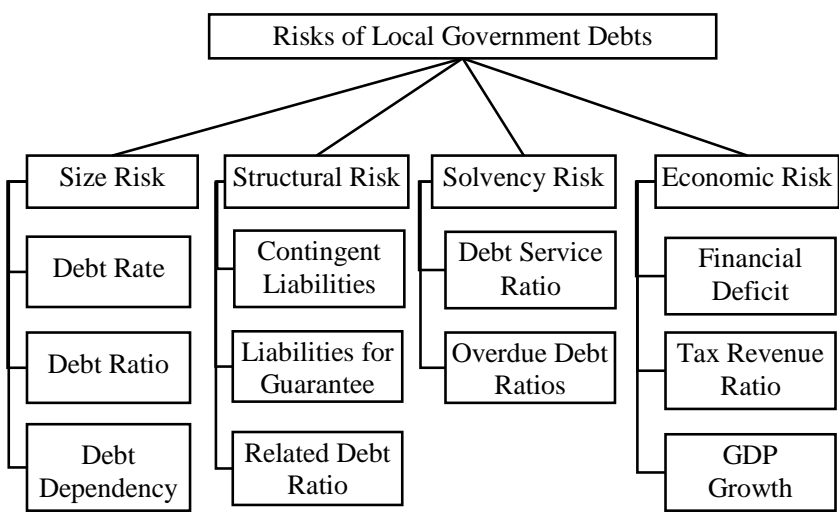

Fig. 1 The proposed model for risks assessment of local government debts
Then, the risks assessment and warning system of local government debts is presented in the following matrix:

$\left|\begin{array}{llllllll}(1.000,1.000, & 1.000) & (0.167, & 1.000, & 0.333) & (0.667, & 2.000, & 0.143) \\ (1.000,1.000, & 1.000) & (0.200, & 2.000, & 0.500) & (0.500, & 3.000, & 0.167) \\ (1.000,1.000, & 1.000) & (0.250, & 3.000, & 0.143) & (0.667, & 2.000, & 0.333) \\ (3.000,1.000, & 6.000) & (1.000, & 1.000, & 1.000) & (0.500, & 1.000, & 5.000) \\ (2.000,0.500, & 5.000) & (1.000, & 1.000, & 1.000) & (0.250, & 4.000, & 6.000) \\ (7.000,0.333, & 4.000) & (1.000, & 1.000, & 1.000) & (0.125, & 5.000, & 2.000) \\ (7.000,0.500, & 1.500) & (0.200, & 1.000, & 2.000) & (1.000, & 1.000, & 1.000) \\ (6.000,0.333, & 2.000) & (0.167, & 0.250, & 4.000) & (1.000, & 1.000, & 1.000) \\ (3.000,0.500, & 1.500) & (0.500, & 0.200, & 8.000) & (1.000, & 1.000, & 1.000)\end{array}\right|$

After the normalization of debts risk factors data, it realized the risk assessment and warning based on the fuzzy theory, the membership function, the meaning of fuzzy set and AHP method respectively. The matrix model was established according to the inducing and analyzing of collected data in the following matrix.

\begin{tabular}{|llllllllll}
$(1.000$ & 1.000 & $1.000)$ & $(0.206$ & 2.000 & $0.325)$ & $(0.611$ & 2.333 & $0.214)$ \\
$(4.000$ & 0.611 & $5.000)$ & $(1.000$ & 1.000 & $1.000)$ & $(0.292$ & 3.333 & $4.333)$ \\
$(5.333$ & 0.444 & $1.667)$ & $(0.289$ & 0.483 & $4.667)$ & $(1.000$ & 1.000 & $1.000)$
\end{tabular} \mid have:

According to the above formula calculation of FAHP, we

$$
\begin{aligned}
\mathrm{S}_{1} & =(1.817,5.333,1.540) \otimes(1 / 19.206,1 / 12.206,1 / 13.731) \\
& =(0.095,0.437,0.112) ; \\
\mathrm{S}_{2} & =(5.292,4.944,10.333) \otimes(1 / 19.206,1 / 12.206,1 / 13.731) \\
& =(0.276,0.405,0.753) ; \\
\mathrm{S}_{3} & =(6.622,1.928,7.333) \otimes(1 / 19.206,1 / 12.206,1 / 13.731) \\
& =(0.345,0.158,0.534) .
\end{aligned}
$$

Next, the following weight vectors are obtained:

$$
W^{\prime}=(1.000,0.954,0.511)
$$

Then, by the process of the normalized weight vectors of objective with respect to the risks assessment criteria are obtained as:

$$
W=(0.406,0.387,0.207)
$$


So we still should go through the same part of the procedure in the following.

$$
\begin{aligned}
& W_{11}=(0.313,0.227,0.106,0.354) \\
& W_{21}=(0.406,0.387,0.207) \\
& W_{22}=(0.328,0.423,0.249) \\
& W_{23}=(0.426,0.574) \\
& W_{24}=(0.316,0.223,0.461) \\
& W=(0.127,0.121,0.065,0.074,0.096,0.057,0.045,0.061, \\
& 0.112,0.079,0.163)
\end{aligned}
$$

But once it completes its calculation, it might have to the results of priority values for risks assessment and warning system in Table III.

TABLE III. THE PRIORITY VALUES FOR RISKS ASSESSMENT AND WARNING SYSTEM

\begin{tabular}{llll}
\hline Attributes & Weight & Sub-attributes & Weight \\
\hline $\begin{array}{l}\text { Size Risk } \\
(0.313)\end{array}$ & 0.406 & Debt Rate & 0.127 \\
& 0.387 & Debt Ratio & 0.121 \\
& 0.207 & Debt Dependency & 0.065 \\
$\begin{array}{l}\text { Structural Risk } \\
(0.227)\end{array}$ & 0.328 & Contingent Liabilities & 0.074 \\
& 0.423 & Liabilities for Guarantee & 0.096 \\
& 0.249 & Related Debt Ratio & 0.057 \\
$\begin{array}{l}\text { Solvency Risk } \\
(0.106)\end{array}$ & 0.426 & Debt Service Ratio & 0.045 \\
& 0.574 & Overdue Debt Ratios & 0.061 \\
$\begin{array}{l}\text { Economic Risk } \\
(0.354)\end{array}$ & 0.316 & Financial Deficit & 0.112 \\
& 0.223 & Tax Revenue Ratio & 0.079 \\
& 0.461 & GDP Growth & 0.163 \\
\hline
\end{tabular}

So it may be concluded that GDP Growth, Debt Rate and Debt Ratio were the first three elements. So we can use scientific research method to assessment the situation, provide reasonable warning information of debts risks to the local government. It is clear that local government have interpreted the requirement to report on the importance of risks assessment and warning system in a variety of ways.

\section{CONCLUSIONS}

Over the last two decades a global wave of reform has taken place against a background of far-reaching economic and a radical reconstruction of local government debts policy. In this paper, we have shown that local government debts do not hold for local public finance when good estimations of risks cannot be provided for some reason. Local governments will inevitably play an important role in economic progress in the future. Some problems on fuzzy consistent judgment matrix of FAHP is presented in this paper.

On the other hand, most of the studies on risks assessment and warning system of local government debts have used statistical methods to arrive at a conclusion. The risks assessment of local government debts described in this paper seem to have prompted some restructuring of economic construction and on various fronts. We hope that future research will build on this idea and explore more novel ways and methods.

\section{ACKNOWLEDGMENT}

This work was supported by the national social science foundation in China (No.14BGL045), major projects in social science planning in Fujian Province (No.2014JDZ034), Social science project in Fujian Province (No.FJ2016C205), and Public welfare soft science research project in Wenzhou city (No. R20160006).

\section{REFERENCES}

[1] Wolfe A. China's Local Government Debt Crisis: A Solutions Manual[J]. Legislative Studies Quarterly, 2010, 35(4):543-569.

[2] Guess G M, Ma J. The Risks of Chinese Subnational Debt for Public Financial Management[J]. Public Administration and Development, 2015, 35(2):128-139.

[3] Sibert A. Rating agencies: role and influence of their sovereign credit risk assessment in the Euro area[J]. European Parliament, 2012.

[4] Aldamen H, Duncan K, Mcnamara R. Corporate governance, risk assessment and cost of debt[J]. Faculty of Business Publications, 2010.

[5] Abel I, Kobor A. Fiscal Sustainability Risk Assessment with Macroeconomic Factors[J]. Ssrn Electronic Journal, 2011.

[6] Chatterjee S. A structure-based software reliability allocation using fuzzy analytic hierarchy process A structure-based software reliability allocation using fuzzy analytic hierarchy process[J]. International Journal of Systems Science, 2015, 46(3):513-525.

[7] Kia S, Sebt M H, Shahhosseini V, et al. Fuzzy Analytic Hierarchy Process in Environmental Management and Estimating Construction Waste Generation Index in Building Construction Projects; Case Study Tehran[J]. Publications of the Astronomical Society of the Pacific, 2015, 119(859):939-961.

[8] Abdullah L, Najib L. Sustainable energy planning decision using the intuitionistic fuzzy analytic hierarchy process: choosing energy technology in Malaysia[J]. International Journal of Sustainable Energy, 2016, 35(4):360-377.

[9] Bulut E, Duru O, Koçak G. Rotational priority investigation in fuzzy analytic hierarchy process design: An empirical study on the marine engine selection problem[J]. Applied Mathematical Modelling, 2015, 39(2):913-923.

[10] Calabrese A, Costa R, Levialdi N, et al. A fuzzy analytic hierarchy process method to support materiality assessment in sustainability reporting[J]. Journal of Cleaner Production, 2016, 121:248-264. 